\title{
Steep Embankment Treatment Technology of Algeria North-South Expressway
}

\author{
Daiguang Chen"2,a, Likui Huang1,b, Enkuan Tang, ${ }^{2, c}$, Qing Shen ${ }^{1, d}$, Zhihao Liü,e \\ ${ }^{1}$ College of Civil Engineering, Hunan University, China \\ ${ }^{2}$ China Construction Fifth Engineering Bureau Co. LTD
}

a'Chen_daiguang@cscec.dz, bhuagnlikui@hnu.edu.cn , ctang_enkuan@cscec.dz

dgniqnehs@163.com, eliuzhihao@hnu.edu.cn

Keywords: Steep embankments; slide-resistant shovel; treatment techniques; expressway

Abstract: The Algeria North-South Expressway from Chiffa to Berrouaghia is located in Blida province and Médéa province in northern Algeria. It is the starting section of Algeria North-South Expressway in the Algeria national arterial highway networks composed of two latitudinal and one longitudinal highway. As an important part of the main highway skeleton in Algeria, the expressway from Chiffa to Berrouaghia is responsible for the main function of traffic conversion between plateau and coastal areas in the country. The project is mostly located in ridges and mountains with large terrain undulating, so the slopes of highway of partial sections are very steep. There are many similarities and differences between Chinese and Algerian highway design specifications or engineering practices in treating steep embankment problems. This paper introduced the main similarities and differences in treating steep embankment problems in China and Algeria, and emphatically introduced the techniques of slide-resistant shovel for treatment of steep slope embankment in Algeria North-South Expressway project.

\section{Introduction}

The Algeria North-South Expressway from Chiffa to Berrouaghia is located in Blida province and Médéa province in northern Algeria with a full length of $53.6 \mathrm{~km}$. It is the starting section of North-South Expressway in the Algeria national arterial highway networks composed of two latitudinal and one longitudinal highway. As an important part of the main highway skeleton in Algeria, the expressway from Chiffa to Berrouaghia is responsible for the main function of traffic conversion between plateau and coastal areas in the country. The project is mostly located in ridges and mountains with large terrain undulating, so the slopes of highway of partial sections are very steep. There are many similarities and differences between Chinese and Algerian highway design specifications or engineering practices in treating steep embankment problems. This paper introduced the main similarities and differences in treating steep embankment problems in China and Algeria, and emphatically introduced the techniques of slide-resistant shovel for treatment of steep embankment in Algeria North-South Expressway project.

\section{Definition of Steep Embankments}

There are technical specifications about steep embankments in Specifications for Design of Highway Subgrades (JTG D30-2015) in China. When the slope rate of ground exceeds 1:5 (11.3), 
steps on the ground should be excavated. When the slope rate of ground exceeds $1: 2.5\left(21.8^{\circ}\right)$, the embankment at this situation is regard as steep embankment. As a significant structure, the steep embankment should be individually investigated and designed.

The special technical clauses (CCTP B2.8.2.2.5) for Algeria North-South Expressway specify that when the slope rate of ground is greater than or equals to $15 \%\left(8.5^{\circ}\right)$, steps should be excavated on the ground.

\section{Treatment Measures of Steep Embankments}

In the construction of highway projects both in China and Algeria, when the requirements of slope stability or bearing capacity of foundation of subgrade are satisfied, the usual treatment measures such as step excavation, transverse blind drains and laying geotextiles are generally adopted to strengthen steep embankments in order to ensure the safety of subgrade. When the stability of slopes or bearing capacity of foundation is not satisfied, the treatment measures of adjusting slope type and slope rate, and setting up retaining structures are generally adopted to strengthen steep embankments. The most obvious difference in treating steep embankments between China and Algeria is that the slide-resistant shovels are broadly adopted at the slope toes in Algeria, and it is proved an effective treatment technique in ensuring the stability of steep embankments.

\section{Slope Type and Slope Rate}

The preliminarily protocoled programme of slope type for Algeria North-South Expressway from Chiffa to Berrouaghia is that the grade height of fill slopes is $8 \mathrm{~m}$ and the width of the slope platform is $3 \mathrm{~m}$. The slope rates from top to bottom grade are adopted with 1:1.5, 1:1.75 and 1:2 respectively. The slope type and slope rate design of Algeria North-South Expressway are roughly the same as the related specifications in China.

\section{Measures of retaining structures}

In order to resist static earth pressure, ensure stability of slopes and reduce the amount of filling earthwork, measures of retaining structures are generally applied in highway engineering. There are two kinds of common measures of retaining structures in China and abroad.

w Slide-resistant retaining wall is a widely used treatment measure to prevent and control landslides. It is convenient for construction and it is effective in controlling landslides. The most common forms of anti-slide retaining wall are masonry or cement concrete casted structures like shoulder protection, toe protection, road shoulder and embankment retaining wall.

w Slide-resistant pile is a kind of technical measure that uses inlay force of piles in laying into the rock and soil to stabilize sliding. It has the advantages of fewer disturbances to the sliding body, simple operation, short construction period, quick effect, safety and reliability.

\section{Step Excavation}

In Algeria, when the slope rate of original ground is greater than $8.5^{\circ}$ and less than $15^{\circ}$, the loose soil layer on the ground surfaces should be cleared before embankment filling, and the steps should be excavated on the steep grounds. The width of steps should be no less than $3.0 \mathrm{~m}$ and the bottom of the steps should be made with an inward slope of $8 \%$.

When the slope rate of original ground is greater than or equals to $15^{\circ}$, the general method of 
embankment treatment in China is to set layers of geotextile materials in the embankment body. However, in Algeria, when layers of geotextiles are laid, the slide-resistant shovels should be set up at the toe of the slope meanwhile. A general design drawing of steep embankments in Algeria is shown as Fig.1.

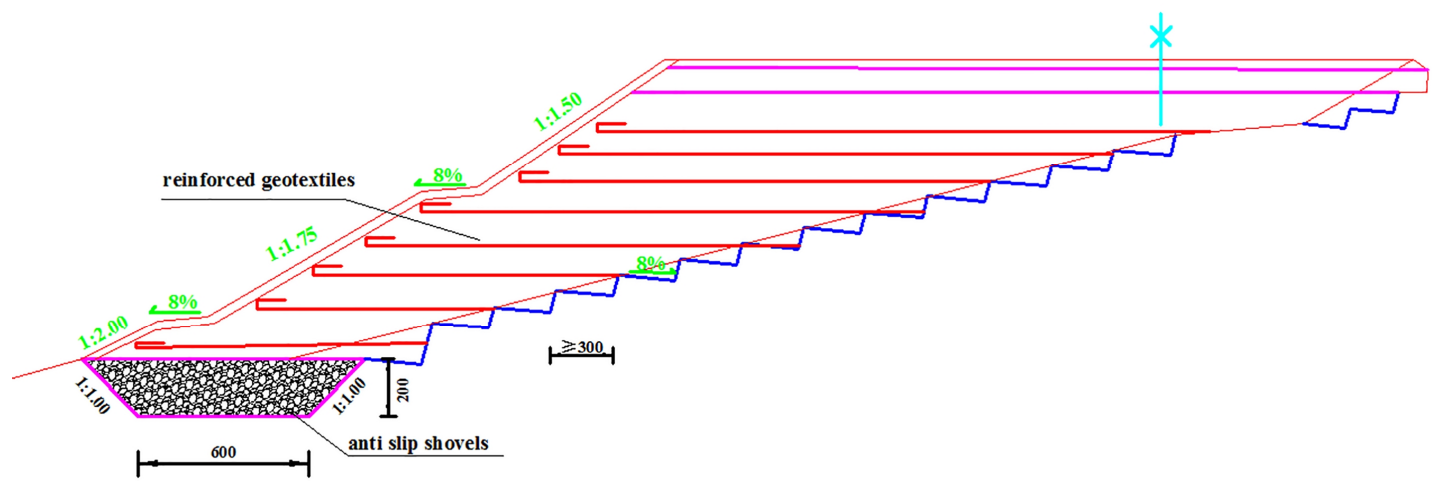

Fig.1 A general design drawing of steep embankments (unit: cm)

\section{Laying Geotextile Materials}

Usually, one layer of geotextile materials is laid every $2 \mathrm{~m}$ spacing. Every layer of geotextiles is laid transversely from the root of steps to point $30 \mathrm{~cm}$ away from the slope surface and reversely laid with one compaction layer thickness in top of the slope. As for fully filling subgrade situation, the geotextiles are laid from the bottom to slope platform of the upper level. As for partly filling subgrade, the geotextiles are laid to the bottom of the PST layer (the roadbed). The tensile strength requirement of high strength geotextile is $150 \mathrm{kN} / \mathrm{m}$, and the maximum elongation is $11 \%$.

\section{Laying Transverse Blind Drain}

As for fully filling subgrades, partly filling and partly excavating subgrades with poor hydrogeological condition, the subgrade specifications both in China and Algeria require setting transverse blind drain. The transverse blind drain can effectively act on drying surface water and improving the strength of foundation and the stability of subgrades. The transverse blind drain is laid every $15 \mathrm{~m}$ to $20 \mathrm{~m}$ along the longitudinal direction. The transverse blind drain should be set as a form of rectangle with $100 \mathrm{~cm} \times 70 \mathrm{~cm}$. The transverse blind drain should be wrapped in permeable geotextiles to play the role of resisting reverse filtration.

\section{Setting Slide-resistant Shovels}

There are no related specifications about the setting of slide-resistant shovels in Specifications for Design of Highway Subgrades (JTG D30-2015) in China. In some cases, due to steep slope or weak strength of the original grounds, the embankment may slide along the basement contact surface or slide within internal foundation. As for this situation, the common practice in Algeria is to set up slide-resistant shovels at the toe of filling subgrade slope. Slide-resistant shovels are set up as inverted trapezoid section. The bottom width of slide-resistant shovels is no less than $6 \mathrm{~m}$ and the depth is no less than $2 \mathrm{~m}$. The slope rate of slide-resistant shovels is 1:1.0. The slide-resistant shovels are filled with GNT 0/100 mm gravels (untreated gravel 0/100 mm) and fully compacted. The outer side of slide-resistant shovels is covered with permeable geotextiles to play the role of filtration. A longitudinal rubble gravel blind drain is set up at the inside bottom of slide-resistant 
shovels. Inside the blind drain there is a perforated PVC drain pipe with the diameter of $15 \mathrm{~cm}$. The transverse PVC pipe is set up to lead to water seepage with an interval of about $15 \mathrm{~m}$. The slide-resistant shovels should be placed on relatively hard layer. Concrete tenon should be set up if the relatively hard layer is not found after a $4 \mathrm{~m}$ deep excavation.

The key construction points of the slide-resistant shovels in detail are described in the following.

Excavation of slide-resistant shovels. The buried depth of slide-resistant shovels is no less than $2 \mathrm{~m}$, so demand of excavation of $2 \mathrm{~m}$ deep under rock stratum foundation with good mechanical property should be satisfied. If there is no rock stratum with good mechanical property, the excavation depth should be determined according to the actual mechanical property in site, so as to ensure that slide-resistant shovels really play the role of preventing landslide of filling subgrades and stabilizing the soil of fill subgrades. Following the requirements of the design drawings, the foot of filling subgrade slope must be located on slide-resistant shovels. Also, the distance of the foot of filling subgrade slope away from the edge of slide-resistant shovels is no less than $2 \mathrm{~m}$, so that the slide-resistant shovels can play the role of stabilizing the foot of the slope and can resist the lateral pressure produced by the soil of filling subgrades.

Excavation of concrete tenon. If no rock stratum with good mechanical property is found after $4 \mathrm{~m}$ deep excavation, the concrete tenon needs to be set up after completion of slide-resistant shovels excavation and site verification of mechanical property by design institute. The tenon must be excavated according to the actual geological and topographic conditions in site. The tenon should be located in the middle of bottom of slide-resistant shovels. The excavation size must be in strict accordance with requirements of the design drawings. Upper part of the tenon is wide and bottom part of the tenon is narrow. Both sides of the tenon should be excavated with a slope rate of 1:6. Usually, the tenon is located in districts with poor geological conditions, so the concrete tenon should be excavated, poured section by section to ensure the shaping of the construction.

Protection and drainage measures of slide-resistant shovels. During excavation of slide-resistant shovels, special attention should be paid to the seepage of mountains to ensure a dry condition and sufficient compactness of basement layer. In the construction of rainy seasons, the temporary truncation sulcus on both sides of the top of slide-resistant shovels should be constructed as soon as possible. In case that rain soaks into internal basement of slide-resistant shovels and makes slide-resistant shovels lose strength, the top of slope of slide-resistant shovels should be leveled up.

Laying geotextiles at the bottom of slide-resistant shovels. The reinforced geotextiles in slide-resistant shovels should be laid in a flat way with an interval of $60 \mathrm{~cm}$ every layer. The main objective of laying geotextiles is to strengthen foundation of foot of slopes. Reinforced geotextiles are laid according to calculating width of each layer. Adjacent geotextiles are directly overlapped with $30 \mathrm{~cm}$ long and direction of the ribs is perpendicular to axis of embankment. When one layer of geotextiles is laid, the rubble aggregates should be laid in a retrograde way to avoid the damage of geotextiles caused by the driving of vehicles directly on geotextiles. Filling thickness of every layer of rubble aggregates is controlled at $30 \mathrm{~cm}$. After two layers of rubble aggregates are filled, reinforced geotextiles are laid on the second layer of rubble aggregates. Repeat the construction procedure above till top of slide-resistant shovels. 
Filling material and compaction of slide-resistant shovels. The filling material of slide-resistant shovels is $0 / 63$ rubble aggregates with good permeability characteristics. Before filling of slide-resistant shovels, the density, water content and the maximum dry density of filling material should be measured. Water content of filling material should be strictly controlled during the compaction process. After finishing the compaction process, compactness of filling material should be checked whether it meets the requirements of design demands. The thickness of every layer of slide-resistant shovels has a great influence on the compactness, so the thickness of every layer must be controlled between $30 \mathrm{~cm}-35 \mathrm{~cm}$ to ensure compactness and stability of slide-resistant shovels.

Filling of slide-resistant shovels in special moist areas. For areas with complex geology and plentiful groundwater, before the filling of slide-resistant shovels, blind sulcus should be set up. The original ground basement should be replaced at a depth of $0.5 \mathrm{~m}$ to $1 \mathrm{~m}$ by rubble aggregates with the size of $15 \mathrm{~mm}$ to $40 \mathrm{~mm}$ or other permeable material. In particularly moist areas, it is very difficult to compact rubble aggregates. In order to improve properties of compacting material of slide-resistant shovels, it is an efficient way by adding lime into rubble aggregates to strengthen the compaction. Also, new types of water absorbent materials can also be used. It can effectively improve the stability of slide-resistant shovels by using improved filling materials to fill initial 1st to 3rd layer of slide-resistant shovels.

\section{Conclusions}

The instability phenomenon of steep embankments is easy to appear in highway engineering, especially in the situation that engineering geological condition and hydrogeological condition of foundation are bad. Based on Algeria North-South Expressway, this paper briefly analyzed the main similarities and differences between China and Algeria in treating steep embankment problems in design specifications and engineering practice, and emphatically introduced techniques of slide-resistant shovels at the slope toes. It is a meaningful technique that is worth learning from for Chinese engineers and technicians.

\section{References}

[1] Algeria North-South Expressway Project of China Construction Corporation. Special technology clauses of Algeria North-South Expressway (CCTP), 2014.

[2] Algeria North-South Expressway Project of China Construction Corporation. Design documents of construction drawings of Algeria North-South Expressway,2015.

[3] People's Republic of China Ministry of transportation and transportation, Specifications for Design of Highway Subgrades(JTG D30-2015), 2015

[4] French specification. Technical Guide for earthwork and cushion construction (GTR), 2000.

[5] D.Q. Zhou, T.S. Yang. Investigation and Design of Steep Slope Embankment on Marl Foundation. Journal of China and Foreign Highway, 2009,(3):307-312.

[6] Y. Wu, X. Jiang, C.L. Jiang. Discussion on The Working Mechanism of Anti Slip Shovel for Embankment on Soft Slope Foundation. Journal of Railway Science and Engineering, 2016, (2):269-275 